\title{
Análise do Acidente de Perda de Refrigerante Primário Devido a Quebra da Linha de Surto do Pressurizador da Usina Nuclear Angra 2
}

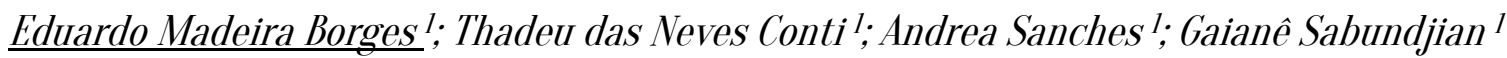

\borges.em@hotmail.com

1. Instituto de Pesquisas Energéticas e Nucleares, IPEN-CNEN/SP.

Histórico do Artigo:

Recebido em: 12 de agosto de 2019

Aceito em: 13 de janeiro de 2020

Publicado em: 30 de abril de 2020

Resumo: 0 objetivo deste trabalho foi simular e avaliar com o código RELAP5 o acidente base de projeto de perda de refrigerante primário devido a uma ruptura média na linha de surto do pressurizador da usina nuclear Angra 2. Este acidente foi uma quebra do tipo guilhotina ou seja $100 \%$ na linha de surto do pressurizador, que representa uma ruptura de $437 \mathrm{~cm}^{2}$. Nesta análise, verificou-se que as lógicas de atuação do Sistema de Proteção do Reator (SPR) e do Sistema de Resfriamento de Emergência do Núcleo (SREN) de Angra 2, utilizadas nesta simulação, funcionaram corretamente, mantendo a integridade do núcleo com as temperaturas do núcleo em níveis aceitáveis durante todo o evento. Os resultados obtidos foram satisfatórios, quando comparados com os apresentados no Relatório Final de Análise de Segurança de Angra 2 (FSAR/A2).

Palavras-chave: Análise de segurança, Reator nuclear, Angra 2, Código RELAP5.

\section{Loss of Coolant Accident Analysis by breaking of the pressurizer surge line of the Angra 2 nuclear power plant}

\begin{abstract}
The aim of this paper was to simulate and assess the basic design accident of $437 \mathrm{~cm}^{2}$ Medium Break Loss of Coolant Accident (MBLOCA) in the surge line of Angra 2 nuclear power plant pressurizer. RELAP5 was used do perform the simulation. It was observed that the Angra 2 Reactor Protection System (RPS) and the Emergency Core Cooling System (ECCS) used in this simulation worked properly, maintaining the integrity of the core with acceptable temperatures throughout the event. Thus, the results were satisfactory when compared with those reported by the Angra 2 Final Safety Analysis Report (FSAR/A2).
\end{abstract}

Keywords: Safety analysis, Nuclear reactor, Angra 2, RELAP5 code.

\section{Análisis de accidente de pérdida de refrigerante primario debido la rotura de la línea de sobretensión del presurizador da planta nuclear Angra 2}

Resumen: El objetivo de este trabajo fue simular y evaluar con el código RELAP5 el accidente de diseño de la pérdida de refrigerante primario debido a una ruptura promedio en la línea de sobrepresión del presurizador de la central nuclear Angra 2. Este accidente fue una falla del tipo de guillotina, es decir, $100 \%$ de tubería y representa una ruptura de $437 \mathrm{~cm}^{2}$. En este análisis, se encontró que la lógica de actuación del Sistema de Protección de Reactores Angra 2 (SPR) y el Sistema de Enfriamiento de Núcleo de Emergencia (SREN), utilizado en esta simulación, funcionó correctamente, manteniendo la integridad del núcleo con el temperaturas centrales a niveles aceptables durante todo el evento. Los resultados obtenidos fueron satisfactorios en comparación con los presentados en el Informe final de análisis de seguridad Angra 2 (FSAR/A2).

Palabras clave: Análisis de seguridad, reactor nuclear, Angra 2, código RELAP5. 


\section{INTRODUÇ̃̃o}

A busca por opções de energias alternativas no mundo tem contribuído para o aumento em investimento e pesquisa nesta área. Uma das fontes de energia considerada limpa é a energia nuclear, que teve um crescimento na última década, no entanto, os acidentes nucleares, como os ocorridos em Three Mile Island em 1979 (COREY, 1979) Chernobyl em 1986 (INTERNATIONAL ATOMIC ENERGY AGENCY, 2005), e mais recentemente em Fukushima em 2011 (GAUNTT et al., 2012), ainda trazem insegurança para a população. Estes eventos aumentaram a pressão por parte dos órgãos reguladores quanto às exigências de segurança em plantas nucleares. Hoje, os órgãos reguladores, internacional e nacional, de controle do uso da energia nuclear, a International Atomic Energy Agency (IAEA) e a Comissão Nacional de Energia Nuclear (CNEN), respectivamente, têm aplicado esforços realizando simulações numéricas com programas computacionais de análise de acidentes em instalações nucleares, com a finalidade de garantir a segurança da população do entorno.

Para atender a estas exigências, as empresas que gerenciam os reatores nucleares nacionais necessitam realizar alguns estudos termo-hidráulicos na área de análise de acidentes e transientes, para que a instalação seja certificada. Isto é feito com a utilização de algumas ferramentas computacionais sofisticadas, ou seja, códigos computacionais tais como: Reactor Excursion and Leak Analysis Program (RELAP5) (IDAH0 NATIONAL LABORAT0RY, 1999), Transient Reactor Analysis Code (TRAC) (SP0RE, 1993), Analysis of THermal-hydraulics of LEaks and Transients (ATHLET) (GESELLSCHAFT FÜR ANGALEN-UND REAKTORSICHERHEIT, 2006), entre outros. A maioria desses programas possui uma filosofia realista, ou seja, tenta retratar de forma mais real possível a fenomenologia dos acidentes e transientes analisados. Todos esses programas foram desenvolvidos segundo essa abordagem, para os reatores refrigerados a água leve do tipo Pressurizer Water Reactor (PWR), Boiling Water Reactor (BWR) e CANadian Deuterium Uranium (CANDU).

No Brasil, a ferramenta escolhida para a realização dos estudos termo-hidráulicos e simulações de acidentes é o código RELAP5. Este programa é muito eficiente na simulação de acidentes em usinas nucleares tais como: a perda de refrigerante primário por pequenas ou grandes rupturas de tubulações, perda de potência elétrica, perda de água na alimentação, entre outros.

A motivação deste trabalho foi: estudar um determinado cenário de acidente que pode ocorrer na usina nuclear Angra 2 e verificar a correta atuação dos sistemas de segurança da 
planta com a manutenção da integridade do núcleo do reator. Para este estudo foi utilizado o código RELAP5, ou seja, o programa foi usado na simulação da planta quando da ocorrência do acidente proposto.

0 objetivo deste trabalho foi simular com o código RELAP5/M0D3.2.2 Gamma (IDAH0 NATIONAL LABORATORY, 1999) o acidente de perda de refrigerante por média ruptura (Medium Break Loss Of Coolant Accident-MBLOCA) na linha de surto do pressurizador de Angra 2 e avaliar as consequências ocorridas no reator. Este acidente está descrito no capítulo 15 do Relatório Final de Análise de Segurança de Angra 2 (Final Safety Analysis Report - FSAR/A2) (ELETRONUCLEAR, 2007). 0 acidente consiste em uma ruptura de $437 \mathrm{~cm}^{2}$, que corresponde a uma quebra do tipo guilhotina na linha de surto do pressurizador, 100\% da tubulação, que liga a perna quente do circuito primário do reator (circuito 20) ao pressurizador. Neste trabalho, foram analisadas as lógicas de atuação do Sistema de Proteção do Reator (SPR) e do Sistema de Resfriamento de Emergência do Núcleo (SREN) de Angra 2, utilizadas nesta simulação, ou seja, foi verificado o funcionamento correto desses sistemas.

A contribuição deste trabalho é significativa, pois permite uma análise independente da CNEN deste acidente, quando comparado com os resultados do fabricante (FSAR/A2), o que o torna inédito.

\section{Reator nuclear Angra 2}

Angra 2 está situado a $150 \mathrm{~km}$ de distância da cidade do Rio de Janeiro, no município de Angra dos Reis. Angra 2 é um reator a água pressurizada (PWR), possui projeto alemão Siemens/KWU, gerando 3.765 MW de potência térmica à pressão nominal de 15,8 MPa, teve sua criticalidade inicial autorizada em julho de 2000 e encontra-se atualmente em operação (ELETRONUCLEAR, 2007).

0 reator nuclear Angra 2, é um PWR com quatro circuitos, cada um deles com um circuito primário, suas tubulações, bomba do primário, gerador de vapor, circuito secundário, sistemas de emergência independentes, entre outros, estão representados na figura 1 (BORGES et al, 2016). Nota-se que o pressurizador está ligado à perna quente do circuito primário (circuito 20), pela linha de surto, onde ocorre a quebra (na parte horizontal da tubulação). 


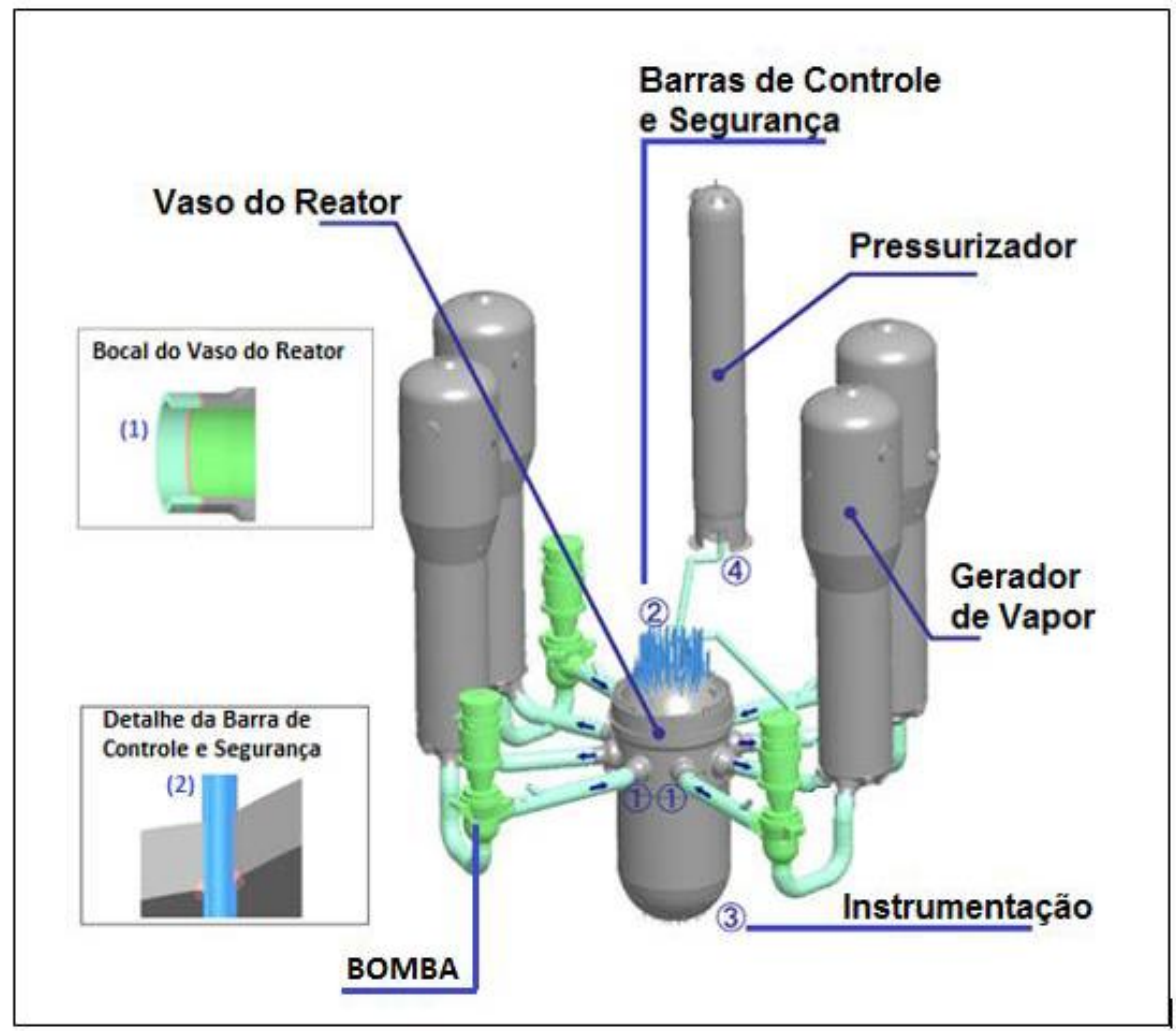

Figura 1. Arranjo dos componentes da Usina Nuclear Angra 2 Fonte: GRIMMEL; CULLEN, 2015.

\section{MATERIAL E MÉTODOS}

0 código RELAP5/M0D3.2.Gamma foi desenvolvido pelo Idaho National Laboratory. Este código foi originalmente projetado para a análise de acidentes e transientes termo-hidráulicos em reatores de água pressurizada (PWR). 0 código RELAP5 tem a capacidade de simular acidentes de perda de refrigerante primário por pequena, média ou grande ruptura (Loss Of Coolant Accident - LOCA). Além disso, também simula transientes de: perda de potência elétrica, perda de água de alimentação, perda de vazão, entre outros. A análise do comportamento termo- hidráulico durante um destes acidentes ou transientes se aplica tanto para o circuito primário como para o secundário de uma instalação nuclear.

0 código possui um modelo de seis equações de conservação, sendo três para cada uma das fases (líquido e vapor), uma equação adicional para gases não condensáveis e uma equação adicional para o tratamento do boro solúvel. Além disso, o programa conta com uma aproximação da equação de conservação de movimento para fluxo transversal e um modelo de fluxo reverso. Este último utiliza uma solução de condução bidimensional. 0 modelo hidrodinâmico é baseado no modelo de volumes de controle para o fluido. 
Estes volumes de controle podem ser considerados como tubos com junções de entrada e saída. Propriedades escalares como pressão, energia, densidade e fração de vazio são representadas pela média dentro do volume de controle e estão localizadas no ponto central do mesmo. Nas junções são utilizadas propriedades vetoriais, tais como, velocidades, vazão mássica, entre outros.

0 modelo de escoamento do RELAP5 utiliza um modelo bifásico, não homogêneo e de não equilíbrio (unidimensional). 0 modelo de transferência de calor também é baseado numa aproximação unidimensional para o cálculo das temperaturas e fluxos de calor.

A estrutura de troca de calor é termicamente conectada ao volume hidrodinâmico por meio de um fluxo de calor que é calculado por meio de uma correlação de transferência de calor por convecção, que depende do tipo de escoamento, e que faz parte do código RELAP5. As estruturas de troca de calor são usadas para simular paredes de tubos, elementos aquecidos, combustíveis nucleares e qualquer superfície de troca de calor (IDAHO NATIONAL LABORATORY, 1999).

De forma geral, para uma simulação com o código RELAP5 necessita-se basicamente das seguintes informações (SILVESTRE, 2016):

- dos dados geométricos da instalação;

- dos dados operacionais;

- dos dados dos materiais que constituem a planta, por meio de tabelas fornecidas pelo usuário ou pela biblioteca interna ao código.

Para a simulação de um acidente ou transiente com o RELAP5 o primeiro passo é a elaboração da nodalização dos componentes hidrodinâmicos da instalação em estudo, que deverão ser modelados por meio da representação geométrica mais próxima da realidade.

Alguns dos componentes existentes no RELAP5 são: PIPE para tubulações, BRANCH para bifurcações ou T’s, VALVE para válvulas, ACCUM para acumuladores, PUMP para bombas, SEPARATOR para separadores de vapor, entre outros. Além dos dados geométricos da planta, que fazem parte dos dados de entrada do código RELAP5, também são modelados os sistemas de controle da planta e as estruturas de troca de calor (B0RGES, 2017). A tabela 1 apresenta alguns dos componentes mais utilizados em simulações de sistemas com o código RELAP5 (SILVESTRE, 2016). 
Tabela 1. Elementos mais utilizados em simulações de sistemas com o RELAP5

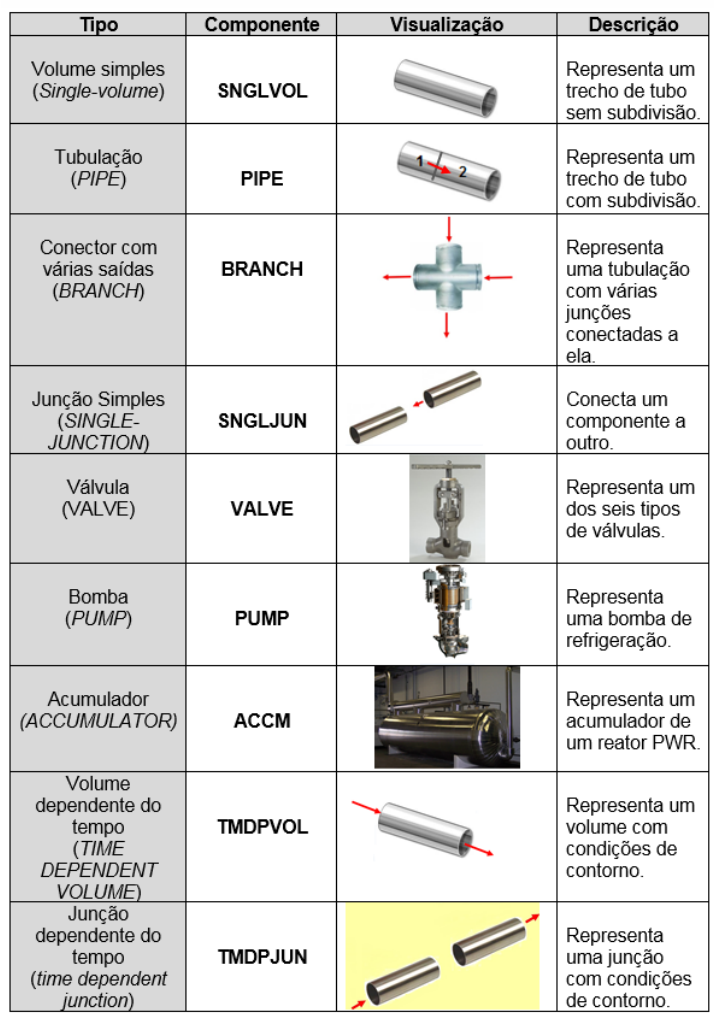

Fonte: Silvestre, 2016.

A usina nuclear Angra 2 foi simulada com base na nodalização definida por B0RGES et al (2002). Observa-se que para cada acidente analisado é necessário realizar alterações na nodalização para representar mais realisticamente cada um dos eventos simulados (BORGES, 2017). Assim sendo, neste caso específico, tem-se:

- $\quad$ o trecho da perna quente do circuito primário 20 ligado a saída do vaso do reator é simulado pelo PIPE 200 com 8 volumes de controle, semelhantemente para os circuitos 10, 30 e 40;

- o componente BRANCH 205 é modelado dessa forma a fim de simular a conexão entre a tubulação do circuito primário e a linha de surto;

- a linha de surto do pressurizador é simulada pelo PIPE 900 com 37 volumes de controle e os BRANCH 901 e 902;

- as válvulas que simulam a quebra MBLOCA tipo guilhotina na linha de surto do pressurizador tem como área de escoamento a área da tubulação da linha de surto $\left(437 \mathrm{~cm}^{2}\right)$. A VALVE 951 liga o BRANCH 901 à contenção (TMDPVOL 960). A VALVE 952 liga o BRANCH 902 à contenção (TMDPVOL 960). A VALVE 953 liga o BRANCH 901 ao 
Análise do Acidente de Perda de Refrigerante Primário Devido à Quebra da Linha de Surto do Pressurizador da Usina Nuclear Angra 2

BRANCH 902. As VALVE 951 e 952 estão fechadas e se abrem no momento do acidente e a VALVE 953 está aberta e se fecha no momento do acidente;

- o pressurizador é simulado pelo PIPE 903 com 2 volumes de controle, BRANCH 906 com 1 volume de controle, PIPE 910 com 16 volumes de controle, BRANCH 914 e BRANCH 915 com 1 volume de controle cada;

- o componente VALVE 917 representa a válvula de alívio do pressurizador conectado ao circuito 20. 0 componente TMDPVOL 920 representa o tanque de alívio do pressurizador;

- o trecho da perna quente do circuito primário 20 compreendido entre a linha de surto do pressurizador e o bocal de entrada do gerador de vapor, GV, é simulado pelo PIPE 210 com 5 volumes de controle, semelhantemente para os circuitos 10, 30 e 40;

- os geradores de vapor GV estão modelados como componentes PIPE e BRANCH e correspondem aos componentes 600 a 699, para o circuito 20 e para os demais circuitos de: 700 a 799, 800 a 899 e 900 a 999, respectivamente;

- o componente PIPE 240, com 19 volumes de controle, simula a perna fria do circuito primário e liga a saída do GV à entrada da bomba de refrigeração do reator do circuito 20, a qual está representada pelo componente PUMP 245, semelhantemente para os circuitos 10, 30 e 40;

- o trecho da perna fria entre a saída da bomba e a entrada do vaso de pressão do reator foi dividido em três componentes, designados respectivamente de PIPE 250, com 4 volumes de controle; BRANCH 255 (155, 355 e 455) com um volume de controle e PIPE 260 com 8 volumes de controle. 0 componente BRANCH 255 é modelado desta forma a fim de simular futuramente a conexão do circuito com o Sistema de Refrigeração de Emergência do Núcleo (SREN), semelhantemente para os circuitos 10, 30 e 40;

- o vaso está representado pelos componentes de 1 a 99 por PIPE e BRANCH;

- o Sistema de Refrigeração de Emergência do Núcleo (SREN) é modelado considerando: oito acumuladores, um para a perna quente de cada circuito 280, um acumulador para a perna fria de cada circuito 286; quatro Tanques de Água Borada (TAP), um em cada circuito 290; quatro Bombas de Injeção de Alta Pressão (BISAP), que injetam água nas pernas quentes, uma em cada circuito 293; e quatro Bombas de Injeção de Remoção de Calor Residual (BRCR), que injetam água nas pernas quentes e frias de cada circuito 297. São também modelados todos os componentes 
que completam o SREN, como tubulações, junções, válvulas, entre outros, designados por: PIPE, BRANCH, TMDPVOL, SINGJUN. TMDPJUN e VALVE, semelhantemente para os circuitos 10, 30 e 40;

- a contenção é representada pelo TMDPVOL 960.

Na tabela 2 é apresentada a descrição da nodalização dos componentes de Angra 2, para a simulação do acidente em questão pelo código RELAP5, conforme figura 2. A figura 2 apresenta a nodalização do circuito 20 do circuito primário de Angra 2, observa-se que a sigla RPV representa o Vaso de Pressão do Reator, PZR é o Pressurizador e SG o Gerador de Vapor. Os outros 3 circuitos são semelhantes (sem o pressurizador), cada qual com a sua numeração específica (circuitos 10, 20, 30, 40). Na simulação de Angra 2 com o RELAP5 é necessário a nodalização e os respectivos dados de entrada para cada um dos 4 circuitos (BORGES et al, 2002).

Tabela 2. Nodalização dos componentes de Angra 2, para o RELAP5

\begin{tabular}{|c|c|c|c|c|}
\hline Trecho da & \multicolumn{2}{|c|}{ Região Hidráulica } & № do componente & Tipo do \\
\hline \multirow{3}{*}{$\begin{array}{l}\text { Circuito 20 } \\
\text { (Circuito 10) } \\
\text { (Circuito 30) } \\
\text { (Circuito 40) }\end{array}$} & \multirow{3}{*}{ Tubulação } & $\begin{array}{l}\text { Perna Fria } \\
\text { GV (20)/Bomba(20) }\end{array}$ & $\begin{array}{c}200 \\
(100,300,400) \\
205 \\
(105,305,405) \\
210 \\
(110,310,410) \\
240 \\
(140,340,440)\end{array}$ & $\begin{array}{c}\text { PIPE } \\
\text { BRANCH } \\
\text { PIPE } \\
\text { PIPE }\end{array}$ \\
\hline & & Bomba & $\begin{array}{c}245 \\
(145,345,445)\end{array}$ & PUMP \\
\hline & & $\begin{array}{l}\text { Perna Fria } \\
\text { Bomba (20) } / \text { aso } \\
\text { do Reator }\end{array}$ & $\begin{array}{c}250 \\
(150,350,450) \\
255 \\
(155,355,455) \\
260 \\
(160,360,460)\end{array}$ & $\begin{array}{c}\text { PIPE } \\
\text { BRANCH } \\
\text { PIPE }\end{array}$ \\
\hline \multirow{4}{*}{ Pressurizador } & \multicolumn{2}{|c|}{ Linha do surto do pressurizador } & $\begin{array}{c}900 \\
901 \text { e } 902 \\
\end{array}$ & $\begin{array}{c}\text { PIPE } \\
\text { BRANCH }\end{array}$ \\
\hline & \multicolumn{2}{|c|}{ Válvulas - quebra tipo guilhotina } & 951,952 e 953 & VALVE \\
\hline & \multicolumn{2}{|c|}{ Vaso do pressurizador } & $\begin{array}{l}903 \\
906 \\
910 \\
914 \\
915\end{array}$ & $\begin{array}{c}\text { PIPE } \\
\text { BRANCH } \\
\text { PIPE } \\
\text { BRANCH } \\
\text { BRANCH }\end{array}$ \\
\hline & \multicolumn{2}{|c|}{ Linha de alivio } & $\begin{array}{l}917 \\
920\end{array}$ & $\begin{array}{l}\text { VALVE } \\
\text { TMDPVOL }\end{array}$ \\
\hline Vaso do Reator & \multirow{2}{*}{\multicolumn{2}{|c|}{$\begin{array}{l}\text { Todos os internos } \\
\text { Tanque de contenção }\end{array}$}} & 1-99 & PIPE e BRANCH \\
\hline Contenção & & & 960 & TMDPVOL \\
\hline $\begin{array}{l}\text { Geradores de } \\
\text { Vapor }\end{array}$ & \multicolumn{2}{|c|}{ Todos os internos } & $\begin{array}{c}500-599 \text { (circuito } \\
10 \text { ) } \\
600-699 \text { (circuito } \\
20 \text { ) } \\
700-799 \text { (circuito } \\
30 \text { ) } \\
800-899 \text { (circuito } \\
40 \text { ) }\end{array}$ & PIPE e BRANCH \\
\hline \multirow[t]{6}{*}{$\begin{array}{l}\text { Sistema de } \\
\text { Refrigeração de } \\
\text { Emergência do } \\
\text { Núcleo (SREN) }\end{array}$} & \multicolumn{2}{|c|}{ Acumuladores } & $\begin{array}{c}280 \\
(180,380,480) \\
286 \\
(186,386,486) \\
\end{array}$ & ACCUM \\
\hline & \multicolumn{2}{|c|}{ Tanques de água borada (TAP) } & $\begin{array}{c}290 \\
(190,390,490)\end{array}$ & TMDPVOL \\
\hline & \multicolumn{2}{|c|}{$\begin{array}{l}\text { Bombas de injeção de alta } \\
\text { pressão (BISAP) }\end{array}$} & $\begin{array}{c}293 \\
(193,393,493)\end{array}$ & TMDPJUN \\
\hline & \multicolumn{2}{|c|}{$\begin{array}{l}\text { Bombas de injeção de } \\
\text { remoção de calor residual } \\
\text { (BRCR) }\end{array}$} & $\begin{array}{c}297 \\
(197,397,497)\end{array}$ & TMDPJUN \\
\hline & \multicolumn{2}{|c|}{ Conexão } & $\begin{array}{c}295 \\
(195,395,495)\end{array}$ & SNGLJUN \\
\hline & \multicolumn{2}{|c|}{ Tubulaçöes } & $\begin{array}{c}282 \\
(182,382,482) \\
288 \\
(188,388,488)\end{array}$ & PIPE \\
\hline
\end{tabular}

Fonte: Elaboração própria. 


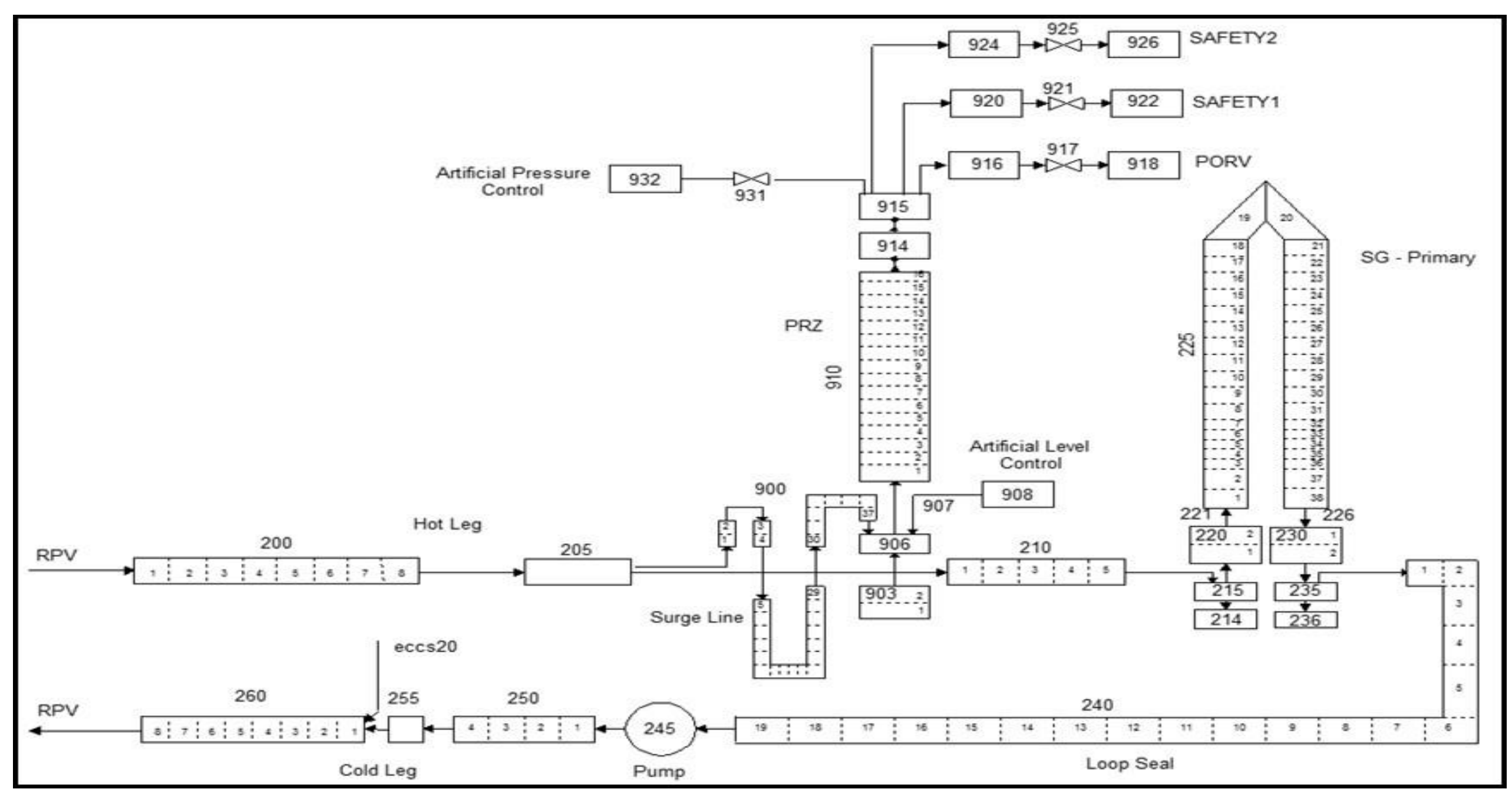

Figura 3. Nodalização do Vaso de Pressão do Reator de Angra 2 Fonte: Elaboração própria. 
0 acidente analisado é uma quebra guilhotina na tubulação da linha de surto que liga o pressurizador à perna quente do circuito primário 20 do reator Angra 2. 0 acidente ocorre aos 100 segundos de simulação, os outros circuitos se mantém intactos, e o evento é simulado até 1100 s. A figura 4 apresenta os componentes 901 e 902 (BRANCH) que representam pedaços da tubulação da linha de surto que ligam o pressurizador à perna quente do circuito primário 20 do reator Angra 2. Quando a quebra ocorre as válvulas 951 e 952 (VALVE) são abertas, e no mesmo instante a válvula 953 (VALVE) é fechada impedindo, assim, o escoamento pela tubulação que se rompeu. Estas válvulas, com áreas de escoamento definidas pelo tamanho da quebra que se quer simular conectam as tubulações rompidas à contenção, componente 960 (SINGVOL).

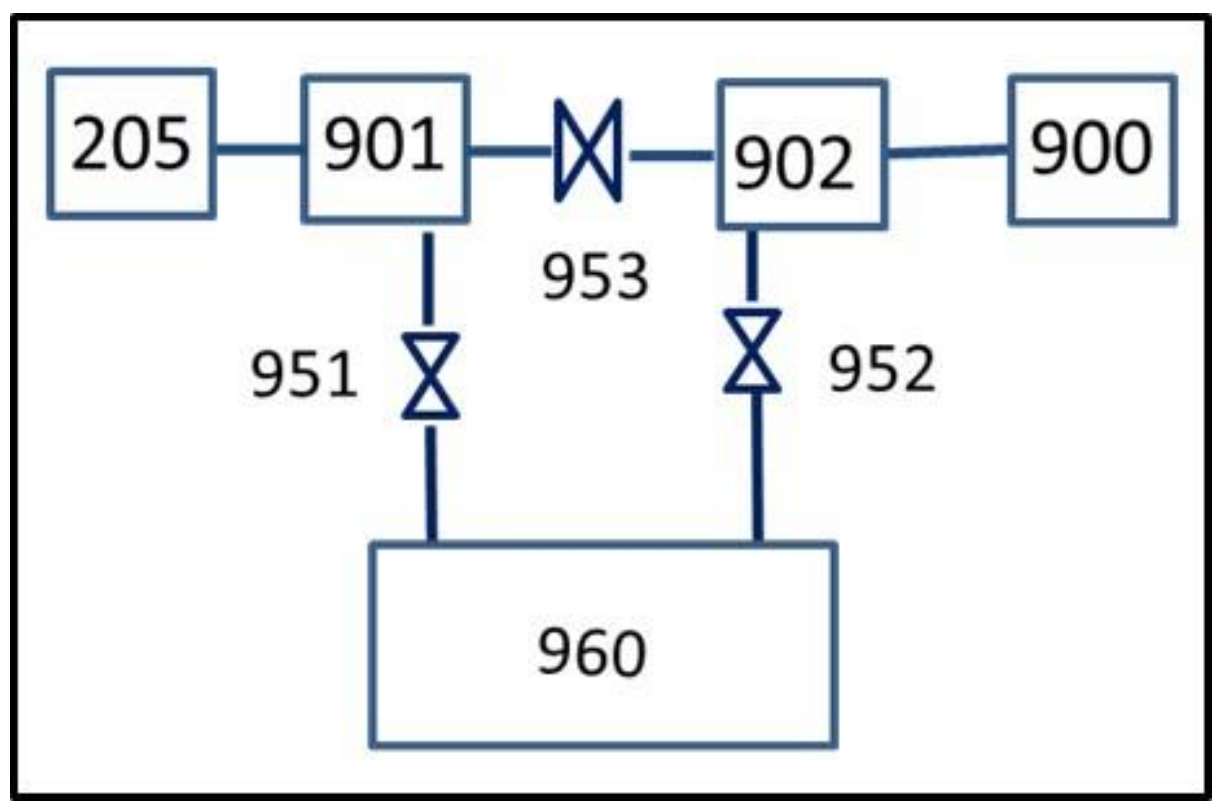

Figura 4. Quebra guilhotina na linha de surto do pressurizador Fonte: Elaboração própria.

\section{Condições iniciais e de contorno}

As condições iniciais e de contorno adotadas na simulação deste acidente seguem aquelas especificadas no RFAS/A2 (ELETRONUCLEAR, 2007). Estas condições são gerais para todos os casos de LOCA do RFAS/A2 (SABUNDJIAN, 2016). As condições operacionais e de atuação dos sistemas de emergência da usina nuclear Angra 2 são detalhados a seguir:

- reator operando a 106\% da potência nominal quando da simulação de um LOCA, cujas condições iniciais encontram-se na tabela 2 (no RFAS/A2 todas as análises de LOCA foram realizadas de forma conservativa a 106\% de potência); 
- núcleo do reator na condição de início de ciclo, para o ciclo de equilíbrio (i.e., 6 dias de equilíbrio com operação a plena potência e queima de $0,2 \mathrm{MWd} / \mathrm{Kg}$ );

- perfil axial da potência do tipo top skewed (potência maior no topo);

- calor de decaimento seguindo a tabela ANS79-1, com um fator multiplicativo de 1,08;

- sinal de desligamento (scram) do reator: conservativamente considerado o segundo sinal de desligamento, desprezando-se o $1^{0}$ sinal;

- reatividade de $\operatorname{scram}$ (para desligamento do reator): reatividade equivalente de todas as barras com exceção da barra mais reativa; adicionalmente está sendo considerado um atraso de 0,2s para início da queda das barras e 2s de tempo de queda das barras;

- assumida a condição de indisponibilidade de potência externa, ocorrendo no mesmo instante do desligamento do reator e do isolamento da turbina;

- consideração do critério de falha e reparo para os geradores a diesel dos circuitos 30 e 40, o que provoca a indisponibilidade das bombas de injeção de alta pressão e de Remoção de Calor Residual do SREN conectado a estes circuitos;

- desligamento (coastdown) das bombas de refrigeração do reator concomitante com a perda da potência externa;

- considerado o resfriamento do secundário a uma taxa de - $100 \mathrm{~K} / \mathrm{h}$, quando a pressão do primário (pRCS) < 13,2 MPa e a da contenção pcont > 0,103 Mpa;

- critério de atuação do SREN: 2 de 3 sinais; pcont > 0,103 MPa; pRCS < 11,0 MPa; nível do pressurizador $(\mathrm{LPZR})<2,28 \mathrm{~m}$;

- critério para a bomba de injeção de alta pressão (BISAP): critério do SREN atingido, +32s de atraso devido a condição de indisponibilidade de potência externa, $+5 \mathrm{~s}$ de atraso para a partida da bomba;

- critério para a bomba de remoção de calor residual (BRCR): $\mathrm{pRCS}<1,0 \mathrm{MPa},+37 \mathrm{~s}$ de atraso devido ao a condição de indisponibilidade de potência externa, +5 s de atraso para a partida da bomba;

- critério para a injeção de água de alimentação auxiliar: nível do gerador de vapor $(\mathrm{LGV})<5 \mathrm{~m}$.

As condições iniciais adotadas são apresentadas na tabela 3 (SABUNDJIAN, 2016). 
Tabela 3. Condições iniciais na usina Angra 2 a 106\% de potência nominal

\begin{tabular}{|c|c|c|c|c|c|}
\hline \multirow[t]{2}{*}{ PARÂMETRO } & \multirow[t]{2}{*}{ UNIDADE } & \multirow[t]{2}{*}{ RFAS/A2 } & \multirow[t]{2}{*}{ RELAP5 } & \multicolumn{2}{|c|}{ ERRO (\%) } \\
\hline & & & & OBTIDO & MÁXIMO \\
\hline & & Reator & & & \\
\hline Potência térmica & MW & 3765 & 3768,4 & 0,09 & 2,0 \\
\hline Perda de pressão no vaso & bar & 2,93 & 2,815 & $-3,92$ & 10 \\
\hline Perda de pressão no núcleo & bar & 1,34 & 1,345 & 0,37 & 10 \\
\hline Temperatura na saida do núcleo & $\mathrm{K}$ & 601,25 & 601,18 & $-0,01$ & 0,5 \\
\hline Temperatura na entrada do núcleo & $\mathrm{K}$ & 564,45 & 566,29 & 0,33 & 0,5 \\
\hline Aumento de temperatura no núcleo & $\mathrm{K}$ & 36,80 & 34,89 & $-5,19$ & - \\
\hline Temperatura de saida no vaso & $\mathrm{K}$ & 599,25 & 600,70 & 0,24 & 0,5 \\
\hline Temperatura de entrada no vaso & $\mathrm{K}$ & 564,45 & 566,29 & 0,33 & 0,5 \\
\hline Aumento de temperatura no vaso & $\mathrm{K}$ & 34,8 & 34,41 & $-1,12$ & - \\
\hline Vazão de refrigerante no núcleo & $\mathrm{kg} / \mathrm{s}$ & 17672,0 & 17671,00 & $-0,01$ & 2,0 \\
\hline Vazão de desvio do núcleo & $\mathrm{kg} / \mathrm{s}$ & 846,00 & 845,69 & $-0,04$ & 10,0 \\
\hline Vazão de desvio pernas fria-quente & $\mathrm{kg} / \mathrm{s}$ & 188,00 & 188,21 & 0,11 & 10,0 \\
\hline Vazão na cabeça do vaso & $\mathrm{kg} / \mathrm{s}$ & 94,00 & 93,98 & $-0,02$ & 10,0 \\
\hline \multicolumn{6}{|c|}{ Gerador de Vapor } \\
\hline Pressão de vapor na saída & bar & 64,5 & 64,50 & 0,0 & 0,1 \\
\hline Perda de pressão no primário & bar & 2,33 & 2,63 & 12,88 & 10,0 \\
\hline $\begin{array}{l}\text { Temperatura da água de } \\
\text { alimentação }\end{array}$ & $\mathrm{K}$ & 491,15 & 491,15 & 0,0 & 0,5 \\
\hline $\begin{array}{l}\text { Vazão mássica da água de } \\
\text { alimentação }\end{array}$ & $\mathrm{kg} / \mathrm{s}$ & 513,9 & 513,90 & 0,0 & 2,0 \\
\hline Vazão mássica de vapor & $\mathrm{kg} / \mathrm{s}$ & 513,9 & 512,34 & $-0,30$ & 2,0 \\
\hline Vazão mássica de recirculação & $\mathrm{kg} / \mathrm{s}$ & 1541,7 & 1541,3 & $-0,03$ & 10,0 \\
\hline Nivel de liquido & $\mathrm{m}$ & 12,2 & 12,34 & $0,14 \mathrm{~m}$ & $0,1 \mathrm{~m}$ \\
\hline Energia térmica transferida & MW & 945,5 & 944,99 & $-0,05$ & 2,0 \\
\hline \multicolumn{6}{|c|}{ Pressurizador } \\
\hline Pressão & bar & - & 158,41 & & 0,1 \\
\hline Nível de liquido & $\mathrm{m}$ & 7,95 & 7,96 & $0,01 \mathrm{~m}$ & $0,05 \mathrm{~m}$ \\
\hline \multicolumn{6}{|c|}{ Circuito Primário } \\
\hline Pressão na Perna Quente & bar & 158,0 & 158,11 & 0,07 & 0,1 \\
\hline Temperatura na Perna Quente & $\mathrm{K}$ & 599,25 & 600,72 & 0,25 & 0,5 \\
\hline Temperatura na Perna Fria & $\mathrm{K}$ & 564,45 & 566,29 & 0,33 & 0,5 \\
\hline Vazão mássica do circuito & $\mathrm{kg} / \mathrm{s}$ & 4700,0 & 4699,70 & $-0,01$ & 2,0 \\
\hline Perda de pressão total & bar & 6.5 & 6.37 & -2.00 & 10,0 \\
\hline
\end{tabular}

Fonte: Elaboração própria.

0 Sistema de Refrigeração de Emergência do Núcleo (SREN) foi simulado com todas as Suas principais características. 0 SREN consiste de: 8 acumuladores, que injetam água nas pernas quentes e frias (1 para cada perna, de cada um dos 4 circuitos primários: 10, 20, 30, 40); de 4 Bombas de Injeção de Alta Pressão (BISAP), que injetam água dos 4 Tanques de Água Borada (TAB) - (Vol. 190, 290, 390, 490) nas pernas quentes (1 em cada circuito primário: 10, 20, 30, 40); e de 4 Bombas de Remoção de Calor Residual (BRCR), que também injetam água borada nas pernas quentes e frias (de cada um dos circuitos primários: 10, 20, 30, 40). Observa-se que 0 
Análise do Acidente de Perda de Refrigerante Primário Devido à Quebra da Linha de Surto do Pressurizador da Usina Nuclear Angra 2

pressurizador de Angra 2 encontra-se no circuito primário 20. A figura 5 mostra a nodalização do SREN do circuito primário 20 de Angra 2.

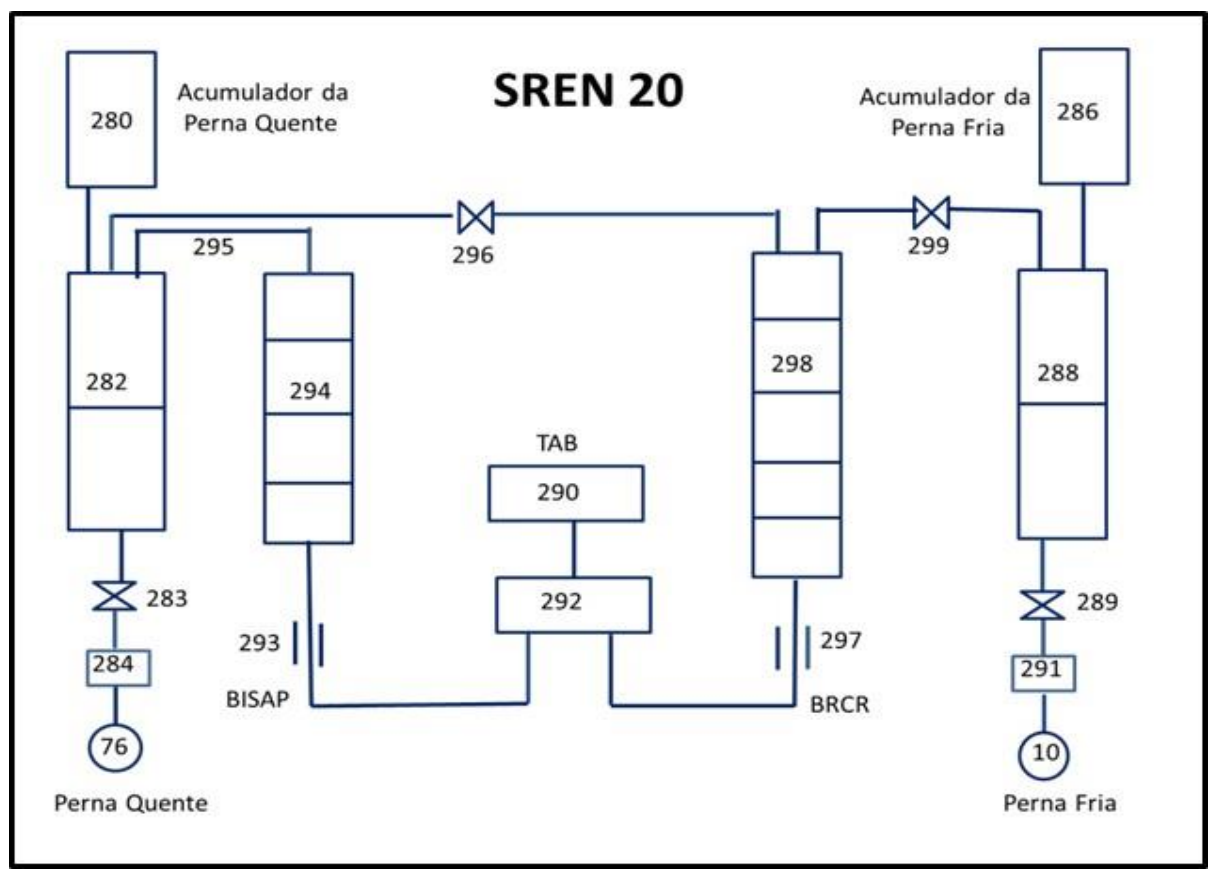

Figura 5. Sistema de Refrigeração de Emergência do Núcleo (SREN - circuito 20) Fonte: Elaboração própria.

Os critérios de operação do SREN neste caso específico são apresentados na tabela $4 \mathrm{e}$ são obedecidos integralmente nesta simulação, conforme definidos no $\mathrm{FSAR} / \mathrm{A} 2$ (ELETRONUCLEAR, 2007). Neste caso, o Sistema de Proteção do Reator foi integralmente simulado todo o por meio da implantação da lógica de atuação descrita no capítulo 7 do FSAR/A2 (ELETRONUCLEAR, 2007). Essa lógica comporta sequencialmente todos os possíveis sinais de desligamento previstos para cada um dos acidentes base de projeto.

Tabela 4. Critérios de operação do Sistema de Refrigeração de Emergência do núcleo

\begin{tabular}{|c|c|c|c|c|c|c|c|c|}
\hline Componentes do SREN & \multicolumn{6}{|c|}{ Sistema de Resfriamento de Emergência do Núcleo } \\
\hline & \multicolumn{2}{|c|}{ Circuito 10 } & \multicolumn{2}{c|}{ Circuito 20 } & \multicolumn{2}{c|}{ Circuito 30 } & \multicolumn{2}{c|}{ Circuito 40 } \\
\hline & $\begin{array}{c}\text { Perna } \\
\text { Quente }\end{array}$ & $\begin{array}{c}\text { Perna } \\
\text { Fria }\end{array}$ & $\begin{array}{c}\text { Perna } \\
\text { Quente }\end{array}$ & $\begin{array}{c}\text { Perna } \\
\text { Fria }\end{array}$ & $\begin{array}{c}\text { Perna } \\
\text { Quente }\end{array}$ & $\begin{array}{c}\text { Perna } \\
\text { Fria }\end{array}$ & $\begin{array}{c}\text { Perna } \\
\text { Quente }\end{array}$ & $\begin{array}{c}\text { Perna } \\
\text { Fria }\end{array}$ \\
\hline $\begin{array}{c}\text { Bombas de injeção de } \\
\text { segurança }\end{array}$ & 1 & - & 1 & - & FD & - & RD & - \\
\hline Acumuladores & 1 & 1 & 1 & 1 & 1 & 1 & 1 & 1 \\
\hline $\begin{array}{c}\text { Bombas de remoção de calor } \\
\text { residual }\end{array}$ & \multicolumn{2}{|c|}{1} & \multicolumn{2}{c|}{1} & \multicolumn{2}{c|}{ FD } & \multicolumn{3}{c|}{ RD } \\
\hline
\end{tabular}

FD: Falha do suprimento de potência a Diesel - RD: Reparo do suprimento de potência a Diesel Fonte: Eletronuclear, 2007. 


\section{RESULTADOS E DISCUSSÃ0}

A tabela 5 apresenta a sequência temporal dos eventos ocorridos durante 0 acidente MBLOCA de $437 \mathrm{~cm}^{2}$, tipo guilhotina, na linha de surto que liga o pressurizador da perna quente do circuito primário 20 do reator Angra 2.

Tabela 5. Sequência de eventos do acidente MBLOCA

\begin{tabular}{|c|c|c|}
\hline \multirow[t]{2}{*}{ EVENTO } & \multicolumn{2}{|l|}{ TEMPO (s) } \\
\hline & $\begin{array}{l}\text { RELAP5/ } \\
\text { MOD3.2.2G }\end{array}$ & RFAS/A2 \\
\hline - Início da ruptura & 100,0 & 100,0 \\
\hline $\begin{array}{l}\text { - Desligamento do reator pelo } 2^{\circ} \text { sinal ( } p_{R C S}<132 \text { bar): } \rightarrow \\
\text { isolamento da turbina, perda de potência externa e desligamento } \\
\text { das bombas do primário. }\end{array}$ & 100,5 & 100,5 \\
\hline $\begin{array}{l}\text { - Resfriamento do lado secundário à taxa de }-100 \mathrm{~K} / \mathrm{h} \text { pelos sinais } \\
\text { de } \mathrm{p}_{\mathrm{RCS}}<132 \text { bar e } \mathrm{p}_{\text {cont }}>1,03 \mathrm{bar}\end{array}$ & 100,5 & 100,5 \\
\hline $\begin{array}{l}\text { - Critério de atuação do SREN atingido }\left(\mathrm{p}_{\mathrm{RCS}}<110 \text { bar e } \mathrm{p}_{\text {cont }}>\right. \\
1,03 \text { bar })\end{array}$ & 104,5 & 105,1 \\
\hline $\begin{array}{l}\text { - Início das bombas de injeção de segurança de alta pressão } \\
\text { (BISAP) }\end{array}$ & 140,0 & 137,6 \\
\hline - Início da injeção pelos acumuladores & 275,0 & 371,0 \\
\hline - Início das bombas de injeção de baixa pressão (BRCR) & 302,0 & 396,0 \\
\hline - Recobrimento do canal quente do núcleo do reator & 400,0 & 450,0 \\
\hline $\begin{array}{l}\text { - Sinal para isolamento dos acumuladores de Perna Fria (500 s } \\
\text { após ter sido atingido o critério do SREN) }\end{array}$ & 604,5 & 605,1 \\
\hline - Término da simulação & 1100,0 & 1100,0 \\
\hline
\end{tabular}

Fonte: Elaboração própria.

Por meio das figuras 1, 2 e 4, observa-se exatamente o local da quebra, e com base nas figuras 5 e tabela 4 pode-se avaliar a atuação do SREN de Angra 2, neste acidente específico.

Alguns dos principais resultados, obtidos na simulação analisada, são apresentados nas figuras 6 a 11.

Na figura 6 observam-se as curvas de pressão do primário e do secundário em Angra 2, que apresentam a despressurização do sistema, que controla a atuação do SREN desse reator. Os resultados obtidos pela simulação do MBLOCA pelo RELAP5/M0D3.2.Gamma e os apresentados pelo FSAR/A2 (ELETRONUCLEAR, 2007) mostram comportamentos semelhantes. Nota-se que a despressurização do primário é aproximadamente igual nos primeiros 50 segundos após o início do acidente e posteriormente se torna mais rápida. Os componentes do SREN de Angra 2 entram em operação em função da variação da pressão do sistema primário. Portanto, na simulação com o RELAP5 a atuação dos acumuladores, que injetam água sob pressão, e das Bombas de Injeção de Baixa Pressão (BRCR), que injetam água borada retirada dos 
Tanques de Água Borada (TAB) - Vol. $(190,290,390,490)$, ocorre antes do respectivos resultados obtidos do SREN do FSAR/A2.

Nas figuras 7 e 8 são apresentadas as curvas da vazão mássica do Sistema de Resfriamento de Emergência do Núcleo (ligado aos circuitos primários - 20 e 30, respectivamente), durante o acidente simulado, com a atuação das Bombas de Injeção de Segurança (de Alta Pressão), de Remoção de Calor Residual (de Baixa Pressão) e, posteriormente a injeção de água pelos acumuladores, neste caso também há também uma defasagem dos resultados do FSAR/A2 e RELAP5. 0 comportamento das curvas obtidas com o código RELAP5 demostram que esse status é pior do que o analisado no FSAR/A2, mostrando, assim, que o circuito é esvaziado antes para este caso, que é mais conservativo, ou seja, dá mais segurança a planta e a população entorno.

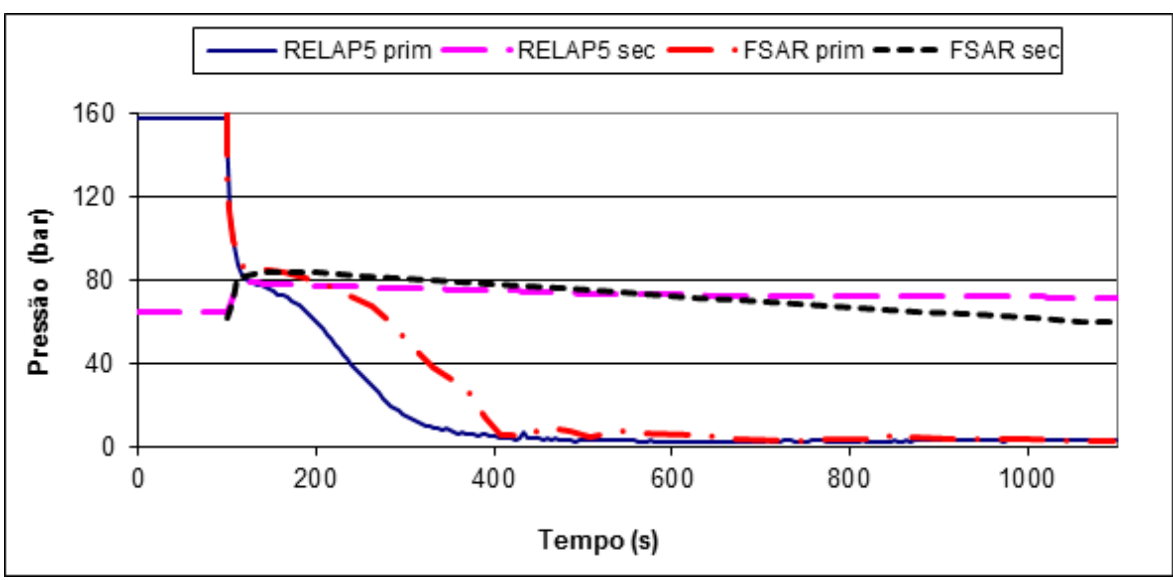

Figura 6. Curvas de pressão dos circuitos primário e secundário de Angra 2 Fonte: Elaboração própria.

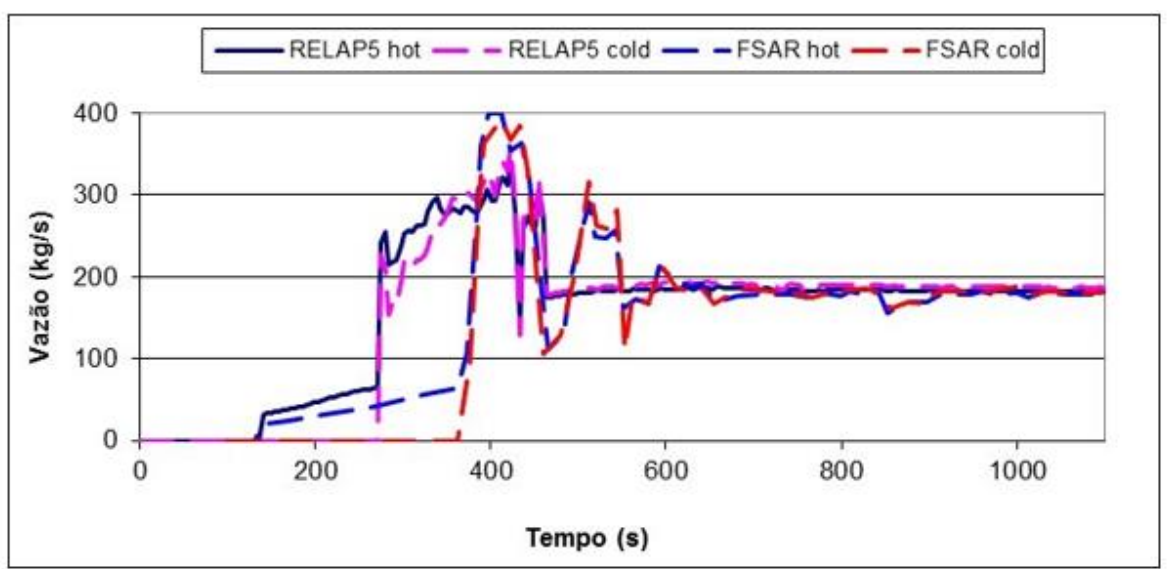

Figura 7. Curvas de vazão em massa do circuito 20 do SREN Fonte: Elaboração própria. 


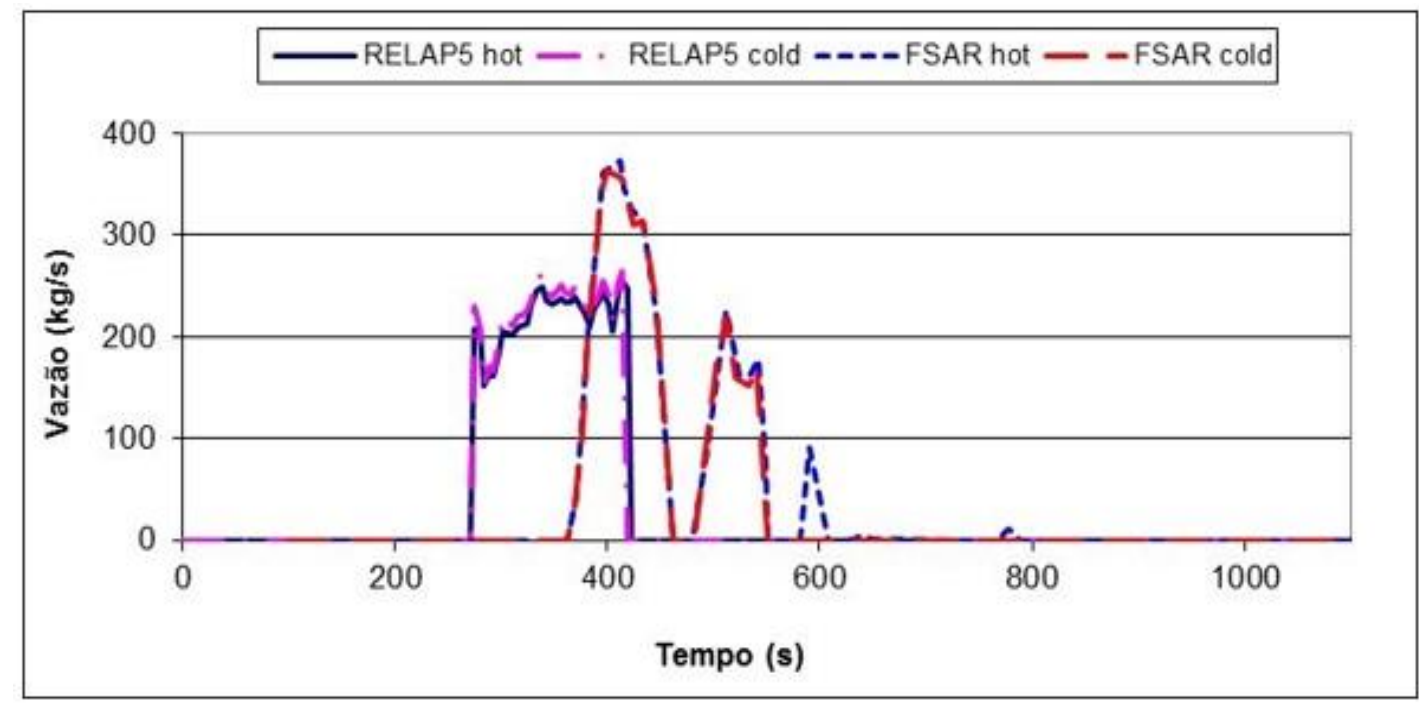

Figura 8. Curvas de vazão em massa do circuito 30 do SREN Fonte: Elaboração própria.

A figura 9 apresenta a comparação entre o RELAP5 e o FSAR/A2 das vazões mássicas da ruptura para a contenção, onde se observa que, ambas as curvas mostram comportamentos parecidos.

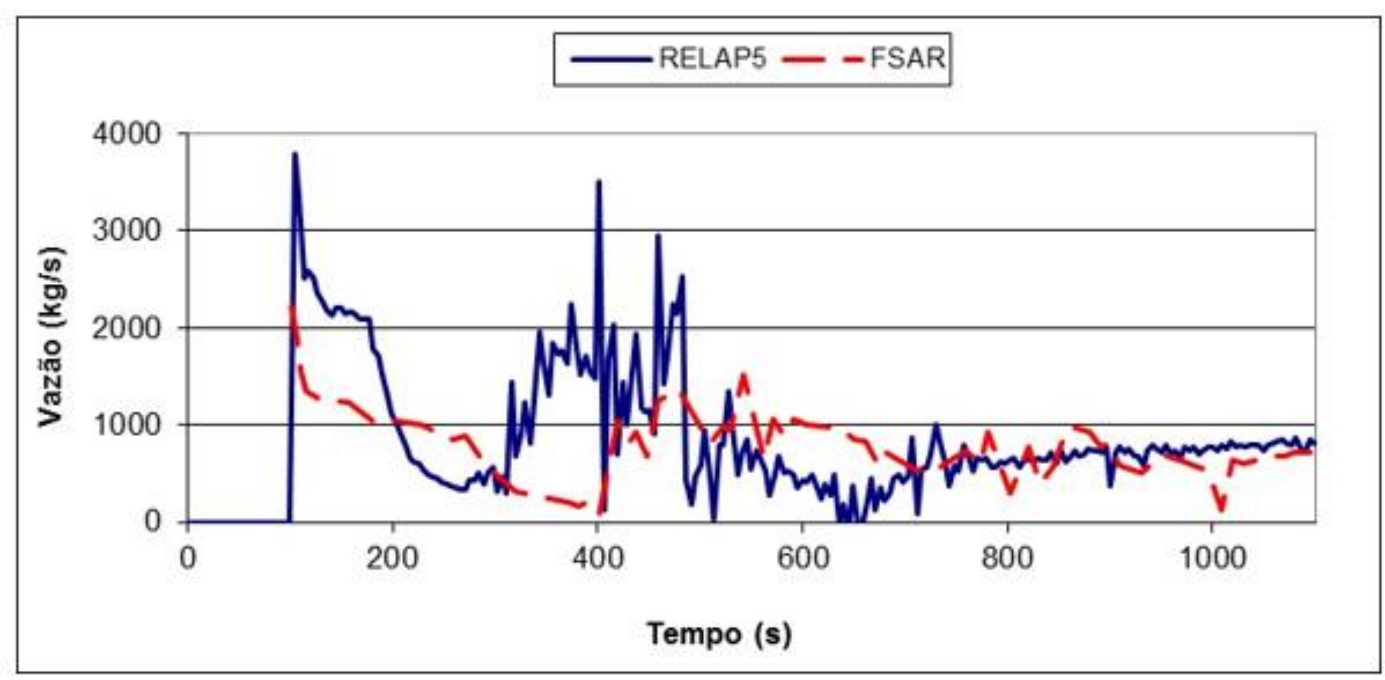

Figura 9. Evolução das vazões mássicas na quebra Fonte: Elaboração própria.

A figura 10 apresenta a fração de vazio na quebra. No caso do RELAP5 há mistura de água-vapor na ruptura. No caso do FSAR/A2, pode-se notar que só há água escoando na quebra após 400 segundos de simulação. 


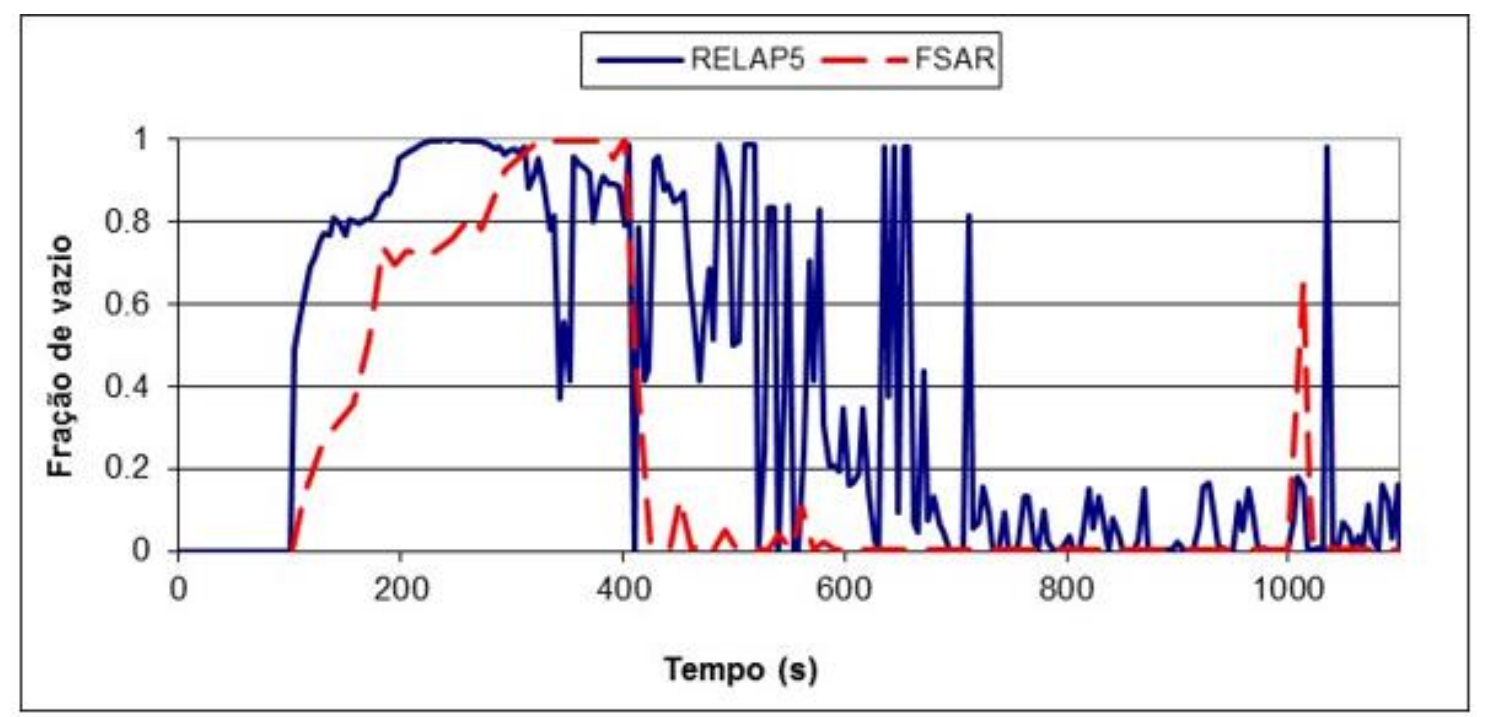

Figura 10. Evolução das frações de vazio na quebra Fonte: Elaboração própria.

A figura 11 apresenta a variação da temperatura em função do tempo na base e na parte superior do revestimento do elemento combustível mais quente do núcleo, sendo que os resultados do FSAR/A2 e do RELAP5 apresentam comportamentos próximos entre si, e que estas temperaturas durante o evento simulado são inferiores às de operação normal do reator Angra 2.

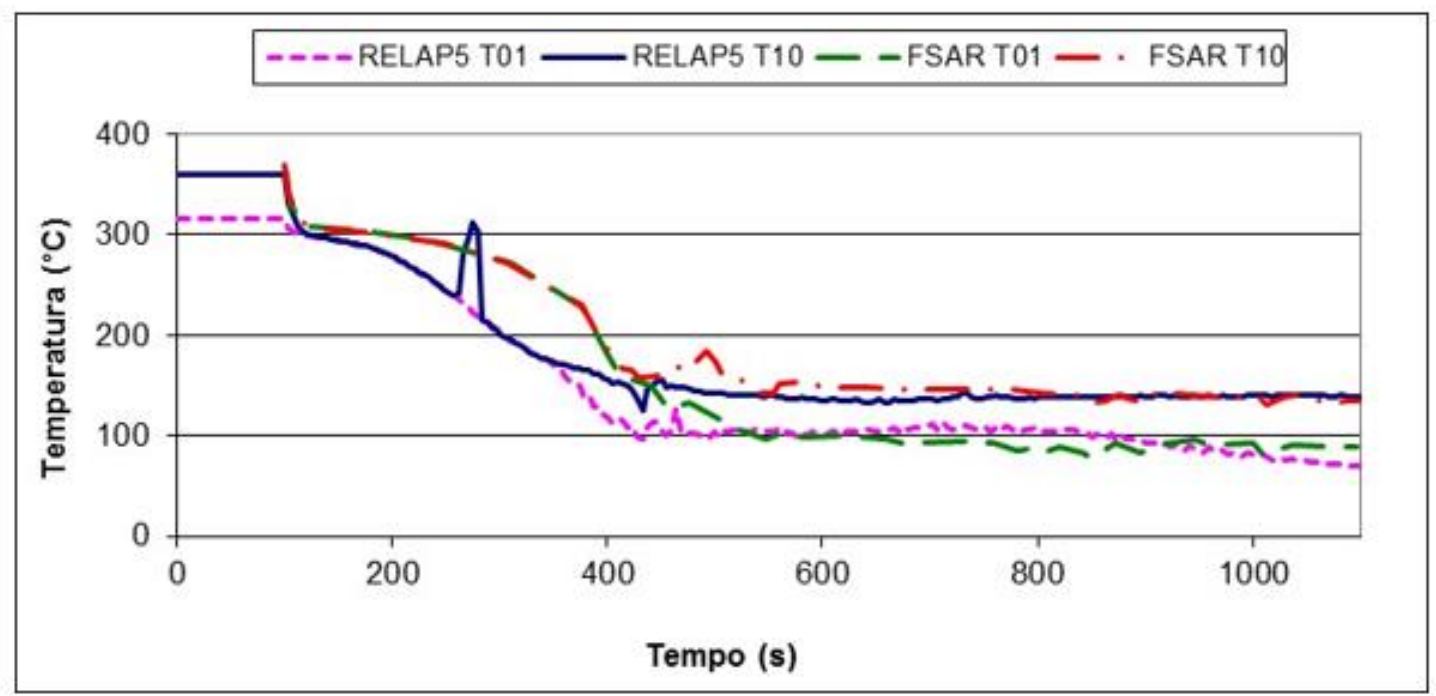

Figura 11. Curvas temperatura na barra quente do núcleo de Angra 2 Fonte: Elaboração própria. 


\section{CONCLUSÃ0}

No caso da usina nuclear de Angra 2, esta é a primeira simulação deste acidente para este reator feita no país, pois os resultados do FSAR/A2 são os da operadora alemã (SIMENS) que utilizou um outro programa computacional, SRELAP5, para a sua análise. Por esta razão, a contribuição deste trabalho é relevante para o órgão licenciador brasileiro, CNEN, pois representa uma análise independente da usina nuclear Angra 2 com código RELAP5.

Os resultados obtidos por meio do código RELAP5, quando da simulação do acidente MBLOCA de $437 \mathrm{~cm}^{2}$ na linha de surto do pressurizador de Angra 2, foram considerados bons quando comparados com os resultados do FSAR/A2. Embora tenham sido apresentadas defasagens em alguns dos resultados do RELAP5 com relação aos do FSAR/A2, demonstram que a integridade do núcleo foi garantida, mesmo considerando os critérios de falha e reparo para os componentes do SREN, que atuou de modo conservativo, conforme previsto no FSAR/A2. Portanto, a modelagem adotada nesse trabalho poderá ser utilizada pela CNEN para uma análise independentemente da usina nuclear Angra 2 e consequentemente no caso da simulação de outros acidentes que venham a ser estudados.

\section{REFERÊNCIAS BIBLIOGRÁFICAS}

BORGES, R.C.; MADEIRA, A.A.; PEREIRA, L.C.M.; PALMIERI, E.T.; AZEVEDO, C.V.G.; LAPA, N.S.; SABUNDJIAN, G.; ANDRADE, D.A. Simulação de ANGRA 2 com o Código RELAP5/Mod3.2.26amma, XIII ENCONTR0 NACIONAL DE FÍSICA DE REATORES E TERMOHIDRÁULICA, 11 a 16 agosto 2002, Rio de Janeiro, 2002

BORGES, E.M., CONTI, T.N., SABUNDJIAN, G. Simulação do Acidente de Perda de Refrigerante na Linha do Sistema de Resfriamento de Emergência do Núcleo, conectada à Perna Fria do Circuito Primário de Angra 2. In: Revista Ciência, Tecnologia \& Ambiente (online), v. 4, p. 45-55, ISSN: 2359-6643. Florianópolis, 2016.

BORGES, E.M. Simulação de Acidentes e Transientes em Angra 2 com o Código RELAP5. 104 p. Relatório Final de PósDoutorado em Tecnologia Nuclear - Instituto de Pesquisas Energéticas e Nucleares IPEN-CNEN/SP. São Paulo, 2017.

COREY, G. R. A brief review of the accident at Three Mile Island: IAEA Bulletin, v. 21, n. 5, p. 54-59, 1979. Disponível em: 〈http://www.iaea.org/publications/magazines/bulletin/bull215/21502795459.pdf〉 Acesso em: 10 dez. 2017.

ELETRONUCLEAR, 2007. Final Safety Analysis Report - Central Nuclear Almirante Álvaro Alberto - Unit 2, Doc. Ident. MA/2-0809.2/060000, Rev. 10, ELETR0NUCLEAR S.A., Rio de Janeiro.

IDAHO NATIONAL LABORATORY. RELAP5/Mod3 Code Manual, Code Structure, System Models, and Solution Methods, NUREG/CR-5535, INEL-95/0174, Volume 1, Idaho National Engineering Laboratory, Idaho, 1999.

GAUNTT, R.; KALINICH, D.; CARDONI, J. Fukushima Daiichi accident study (status as of April 2012), Tech. Rep. SAND2012-6173, Sandia National Laboratories, Albuquerque, NM, USA, 2012. 
Análise do Acidente de Perda de Refrigerante Primário Devido à Quebra da Linha de Surto do Pressurizador da Usina Nuclear Angra 2

GESELLSCHAFT FÜR ANGALEN-UND REAKTORSICHERHEIT, ATHLET Mod. 2.1 Cycle A, Models and Methods. Gesellschaft für Anlagen- und Reaktorsicherheit (GRS) mbH, 2006.

GRIMMELl;W. H. CULLEN, Jr., NRC Project Manager U.S. Plant Experience with Alloy 600 Cracking and Boric Acid Corrosion of Light-Water Reactor Pressure Vessel Materials (NUREG-1823). Disponível em: 〈http://www.nrc.gov/reading-rm/doc-collections/nuregs/staff/srl823//>. Acesso em: 10 out. 2015.

INTERNATIONAL ATOMIC ENERGY AGENCY. Chernobyl's Legacy: Health, Environmental and Socio-Economic Impacts and Recommendations to the Governments of Belarus, the Russian Federation and Ukraine. The Chernobyl Forum: 2003-2005 Second revised version.

MICAELLY, J.; BESTUIB, D. CATHARE, the New Improved French Thermal Hydraulic Code for Safety Reactor Studies. In: INTERNATIONAL ENS/ANS CONFERENCE ON THERMAL REACTOR SAFETY, October 2-7, 1988, Avignon, France, Proceedings... Avignon.

SABUNDJIAN, G. Simulation of Design Basis Accidents, LBLOCAs, in Angra 2 with RELAP5 Code, Technical Report, IPEN-CEN-PSE-DRS-011-00, RELT-001-00, Instituto de Pesquisas Energéticas e Nucleares, São Paulo, 2016.

SILVESTRE, L.J.B. PCRELAP - Programa de Cálculo para os dados de entrada do código RELAP5. Dissertação (Mestrado em Tecnologia Nuclear- Reatores de Potência) Instituto de Pesquisas Energéticas e Nucleares. São Paulo, SP, Brasil, 2016. Disponível em http://www.teses.usp.br. Acessado em 14 de março de 2017.

SP0RE, J.W. et al. TRAC-PFl/M0D2 Code Manual, Volume 1, Theory Manual, NUREG/CR-5673, LA-12031-M, 1993. 